\title{
Decision-making Method for Low-rent Housing Construction Investment
}

\author{
Wei Zhang ${ }^{*}$, Liwen You \\ University of Science and Technology Liaoning, Anshan , Liaoning \\ University of Science and Technology Liaoning, Anshan , Liaoning \\ 156303620@qq.com, 780460082@qq.com
}

\begin{abstract}
Keywords: Developers, Government, Low-rent housing, Multi-stage, Option game
Abstract. The paper sets up a investment decision-making model with the option game thinking. First, based on the option game features low-rent housing projects have, the paper proposes some research hypotheses on value, benefits, costs for the options. Second, on the basis of the decision-making path of a multi-stage binary tree model, respectively for the government and developers, the paper builds utility functions, cost-input models and decision-making models of the contract period. It indicates that by the use of growth options in the shortened contract period, developers can still ensure the quality of low-rent housing construction. Finally, the validity of the model in the low-rent housing agreement and the investment decision-making process is verified by the case analysis.
\end{abstract}

\section{Introduction}

In China, the demand of low-rent housing is far greater than the supply, and to solve the outstanding problem is the fund. Today, the fund of low-rent housing construction is in government-led investment model. To change this single mode, it must be introduced other investment entities in the construction of low-rent housing. By the introduction of this mechanism of competition, the government's financial pressure can not only be reduced, but also the technology and management level can be improved in the low-cost housing construction.

Due to the long investment recovery period and many uncertain factors in the low-rent housing projects, the option game method is used to establish the decision model of determining the contract period, this paper puts forward the investment decision method of multi-stage low-rent housing construction, which brings more flexibility for the decisions of the government and developers. The government has adopted multi-stage low-rent housing projects, namely the winning-bid developer in the first stage can continue to invest in the next stage, whether to choose such investment opportunities and whether such investment opportunities is of the value can be evaluated by growth options. The winning-bid developer determines whether to implement the growth option based on the company's strategic goals, the net cash flow and expected benefits growth options bring and etc. The both sides in the negotiation process will measure the value of the growth option, considering whether it is worth implementing the growth option. The government can investigate the winning-bid developer whether there is sufficient technical capacity and management level during the contract period, in order to determine whether or not to choose the company to continue to invest in the second stage. While the developer can base the company's strategic goals, conditions of investment opportunities and other factors to determine whether to continue the second stage of the investment project. The next stages proceed in turn. In short, the introduction of growth options can not only avoid the risk flexibly, but also bring more choices to both sides.

\section{Building the Model}

Basic Assumptions. The assumptions are as follows: Assumption one: The construction of low-rent housing projects is divided into two stages, the winning-bid developer can perform the growth option of the second stage, whose value is expressed as $\mathrm{Vg}$. 
Assumption two: During the operation of the low-rent housing, P (i.e. the unit rent) should be set by the government, and the price changes over time is negligible. Developers obtain the profits by charging rent, and the difference between the rent and the market level is subsidized by the government.

Assumption three: The annual average of q (i.e. the amount of low-cost housing construction) is a constant. Based on the assumption two, the average annual income is expressed as ${ }_{\mathrm{I}=\mathrm{p} \int \mathrm{f}(\mathrm{q}) d q}$. Here, $\mathrm{f}(\mathrm{q})$ is the distribution function of $\mathrm{q}, \mathrm{I}$ is the average annual income.

Assumption four: The late operational cost includes management cost and annual review cost for qualifications, and the management cost will increase with the low-rent housing over time. The Management cost can be expressed as $\mathrm{C}_{\mathrm{m}}=k t C^{-\beta}(\mathrm{k}>0, \beta>0)$.

Model Building. The government adopts the method that developers involve in the multi-stage investment of low-cost housing projects. The first stage is required for the negotiation about the contract period. For decision variables of the government and developers, we set the contract period as $\mathrm{Tc}$, the construction cost as $\mathrm{C}$, the economic life period of the low-rent housing as $\mathrm{T}$.

By Assumption one, the developer can choose whether to continue to invest in the second stage of the project, based on the expected benefits in the first stage of low-rent housing project. According to the binary tree method in the basic theory of real options, when the contract expires, the value of the first stage of the project may appear as two states, $\mathrm{V}_{1}^{+}$and $\mathrm{V}_{1}$. If the value of the project is up to $\mathrm{V}_{1}{ }^{-}$, the developer will stop to continue to invest the next stage. If the value of the project is up to $\mathrm{V}_{1}^{+}$, the developer will continue to invest in the second stage of the project, setting the investment cost as $\mathrm{C} 2$, and the value of the second stage V2 may also appear as two states, $\mathrm{V}_{2}{ }^{+}$and $\mathrm{V}_{2}{ }^{-}$. Therefore, the value of the investment opportunities of low-cost housing projects is given by:

$$
\begin{aligned}
\mathrm{V}_{\mathrm{g}}^{+} & =\max \left(\mathrm{V}_{1}^{+}, \mathrm{V}_{2}^{+}-C_{2}\right) \\
\mathrm{V}_{\mathrm{g}}^{-} & =\max \left(\mathrm{V}_{1}^{-}, \mathrm{V}_{2}^{-}-C_{2}\right)
\end{aligned}
$$

The investment value of the low-rent housing project containing growth options, $\mathrm{Vg}$ is given by:

$$
\mathrm{V}_{\mathrm{g}}=\frac{\mathrm{PV}_{\mathrm{g}}^{+}+(1-\mathrm{P}) \mathrm{V}_{\mathrm{g}}^{-}}{1+r}-\mathrm{C}
$$

$\mathrm{P}$ is risk neutral probability, $\mathrm{r}$ is the risk-free rate.

In order to benefit the public, the government in the negotiations will first determine the contract period Tc. Then, we can have the decision-making model that decision variable Tc satisfies :

$$
\begin{aligned}
& \max \int_{\mathrm{T}_{\mathrm{C}}}^{\mathrm{T}}\left[\mathrm{p} \int \mathrm{f}(\mathrm{q}) \mathrm{dq}-\mathrm{C}_{\mathrm{m}}\right] d t \\
& \text { s.t. } \int_{0}^{\mathrm{T}_{\mathrm{C}}}\left[\mathrm{p} \int \mathrm{f}(\mathrm{q}) \mathrm{dq}-\mathrm{C}_{\mathrm{m}}\right] d t-C+V_{g} \geq \mu
\end{aligned}
$$

Eq.4 is the utility function of the government to maximize the public interest under the contract period. Eq.5 is the constraint condition which the utility function of the government need to meet, namely that the expected utility developers achieve in the contract period of low-rent housing projects is not less than the maximum expected utility gained by other projects. Where, the maximum expected utility which developers can gain from other projects, namely the opportunity utility, is expressed as $\mu$.

According to the contract period Tc given by the government and the profit maximization, Developers can determine $\mathrm{C}$ (i.e., construction cost), so the decision-making model decision variables $\mathrm{C}$ satisfies:

$$
\max \left\{\int_{0}^{\mathrm{T}_{\mathrm{c}}}\left[\mathrm{p} \int \mathrm{f}(\mathrm{q}) \mathrm{dq}-\mathrm{C}_{\mathrm{m}}\right] d t-C+V_{g}\right\}
$$

Eq. 6 is to ascertain the construction cost C , based on the contract period Tc given by the government and under the condition of profit maximization. The Tc given by the government is often less than the value obtained by the traditional method, even if there are some constraints of growth options, developers may also reduce the input of construction cost.

Solution and Discussion. In order that the benefits of the government and developers can achieve the maximum, we can adopt the backward induction to solve both the decision-making models, that is the 
first to determine $\mathrm{C}$ developers need to invest in accordance with the given $\mathrm{Tc}$, then the government will determine the appropriate $\mathrm{Tc}$ based on $\mathrm{C}$.

First, it is to determine $\mathrm{C}$ developers need to invest in accordance with the given Tc. For Assumption three and Assumption four, substituting $\mathrm{I=p} \int \mathrm{f}(\mathrm{q}) d q$ and $\mathrm{C}_{\mathrm{m}}=k t C^{-\beta}$ into Eq.6 gives the following formula:

$$
\max \left[\int_{0}^{\mathrm{T}_{\mathrm{c}}}\left(\mathrm{I}-\mathrm{ktC} \mathrm{C}^{-\beta}\right) \mathrm{dt}-C+V_{g}\right]
$$

Accordingly, Eq.7 is simplified:

$$
\max \left[\mathrm{IT}_{\mathrm{c}}-\frac{1}{2} k T_{c}^{2} C^{-\beta}-C+V_{g}\right]
$$

Based on the first order condition of the optimization, Eq. 8 can be derived:

$$
\mathrm{C}=\left(\frac{1}{2} \mathrm{k} \beta T_{c}^{2}\right)^{\frac{1}{1+\beta}}
$$

Then, the government will refer to the $\mathrm{C}$ developers pre-estimate, namely determining the appropriate Tc based on $\mathrm{C}$.

Substituting Eq.9 into Eq.4 and Eq.5, thus the decision model and the constraint condition for decision variable Tc can be written:

$$
\begin{aligned}
& \max \left[I\left(T-T_{c}\right)-\int_{T_{c}}^{T}\left(\frac{1}{2}\right)^{\frac{-\beta}{1+\beta}} k^{\frac{1}{1+\beta}} \beta^{\frac{-\beta}{1+\beta}} \mathrm{T}_{c}^{\frac{2-\beta}{1+\beta}} \mathrm{tdt}\right] \\
& \text { s.t. } \mathrm{TT}_{\mathrm{c}}-\int_{0}^{\mathrm{T}_{\mathrm{c}}}\left(\frac{1}{2}\right)^{\frac{-\beta}{1+\beta}} \mathrm{k}^{\frac{1}{1+\beta}} \beta^{\frac{-\beta}{1+\beta}} \mathrm{T}_{\mathrm{c}}^{\frac{2 \beta}{1+\beta}} \mathrm{tdt}-C+V_{g} \geq \mu
\end{aligned}
$$

To solve Eq.10 under the constrain condition of Eq.11, we can use Lagrange multiplier method. Thus, we can construct a Lagrange function with Lagrange multiplier $\lambda$, the function is given by:

$$
\begin{aligned}
& \mathrm{L}_{\left(\mathrm{T}_{\mathrm{c}}, \lambda\right)}=\mathrm{I}\left(\mathrm{T}-\mathrm{T}_{\mathrm{C}}\right)-\int_{\mathrm{T}_{\mathrm{C}}}^{\mathrm{T}}\left(\frac{1}{2}\right)^{\frac{-\beta}{1+\beta}} \mathrm{k}^{\frac{1}{1+\beta}} \beta^{\frac{-\beta}{1+\beta}} \mathrm{T}_{\mathrm{c}}^{\frac{2 \beta}{2+\beta}} \mathrm{tdt} \\
& +\lambda\left[\mathrm{T}_{\mathrm{C}} \mathrm{I}-\int_{0}^{\mathrm{T}_{\mathrm{c}}}\left(\frac{1}{2}\right)^{\frac{-\beta}{1+\beta}} \mathrm{k}^{\frac{1}{1+\beta}} \beta^{\frac{-\beta}{1+\beta}} \mathrm{T}_{\mathrm{c}}^{\frac{2 \beta}{1+\beta}} \mathrm{tdt}-\mathrm{C}+\mathrm{V}_{-\mathrm{g}}-\mu\right]
\end{aligned}
$$

Respectively, Tc and $\lambda$ in Eq.12 can be derived by solving the first order partial derivative:

$$
\begin{aligned}
& \frac{\partial L}{\partial T_{C}}=(\lambda-1) \mathrm{I}+\frac{2 \mathrm{C}}{(1+\beta) \mathrm{T}_{\mathrm{C}}}\left[\frac{\mathrm{T}^{2}}{\mathrm{~T}_{\mathrm{C}}{ }^{2}}-\frac{\lambda+\lambda \beta-1}{\beta}\right]=0 \\
& \frac{\partial L}{\partial \lambda}=I T_{C}-\frac{1+\beta}{\beta} C+V_{g}-\mu=0
\end{aligned}
$$

Solving Eq.14, we obtain:

$$
T_{C}=\frac{1+\beta}{\beta I} C-\frac{V_{g}}{I}+\frac{\mu}{I}=0
$$

Then, we can analyze the relationships between construction cost $C$, contract period $\mathrm{Tc}$ and growth option Vg. Solving the derivative of Eq.9, it results that:

$$
\frac{\partial C}{\partial T_{c}}=\frac{2}{1+\beta}\left(\frac{1}{2} \mathrm{k} \beta\right)^{\frac{1}{1+\beta}} \cdot T_{c}^{\frac{1-\beta}{1+\beta}}>0
$$

We can observe that $\mathrm{C}$ will increase as Tc increases.From Eq.15, we can know that the contract period $\mathrm{Tc}$ is relevant to the construction cost $\mathrm{C}$, the average annual income $\mathrm{I}$, the value of growth option $\mathrm{Vg}$ and the opportunity utility $\mu$. Solving the derivative of Eq.15, it results that:

$$
\frac{\partial \mathrm{T}_{\mathrm{C}}}{\partial \mathrm{V}_{\mathrm{g}}}=-\frac{1}{I}<0
$$

We can observe that Tc will increase as Vg decreases. Hence, the government will extend the contract period Tc to make up for the disadvantage of the growth option Vg. Solving the derivative of Eq.15, it results that:

$$
\frac{\partial \mathrm{T}_{\mathrm{C}}}{\partial \mu}=\frac{1}{I}>0
$$

We can observe that Tc will increase as $\mu$ increases. So the government can extend the contract period Tc to make ROI(i.e., Return on Investment) not less than other investments. Likewise, C will increase as $\mathrm{Vg}$ increases under the given Tc. So developers will increase the investment due to the increased growth option. 


\section{Case Analysis}

A government will prepare to build 2,000 units of low-rent housing, which proceed in two stages. 1200 units will be built in the first stage, and 800 units will be built in the second stage. Given that each set low-rent house is 50 square meters, the cost per square meter is 2,000 yuan, and the central financial subsidy is 1,000 yuan per square meter. So developers are required to pay 1,000 yuan of matching funds. We can conclude that the scale of investment in the first stage of the project is 60 million yuan, and the scale of investment in the second stage is 40 million yuan. A developer has won the bid and started to construct the first stage of the project, its data are shown in the following table.

\begin{tabular}{|l|l|l|l|l|l|l|l|l|}
\hline simbol & $\mathrm{C}$ & $\mathrm{I}$ & $\mu$ & $\mathrm{K}$ & $\mathrm{C} 2$ & $\mathrm{P}$ & $\mathrm{r}$ & $\beta$ \\
\hline data & 60 & 14.4 & 20 & 0.6 & 40 & 0.6 & $6 \%$ & 1.2 \\
\hline
\end{tabular}

Table 1. The data in first stage(million)

When the growth option expires, the value in the first stage of the project is: $\mathrm{V}_{1}^{+}=62, \mathrm{~V}_{1}^{-}=30$. After investing the second stage of the project, $\mathrm{V}_{2}^{+}=120, \mathrm{~V}_{2}^{-}=87$.

According to Eq.1,2,3, we can obtain: $\mathrm{V}_{\mathrm{g}}^{+}=80 \quad \mathrm{~V}_{\mathrm{g}}{ }^{-}=47$ $\mathrm{V}_{\mathrm{g}}=\frac{\mathrm{PV}_{\mathrm{g}}^{+}+(1-\mathrm{P}) \mathrm{V}_{\mathrm{g}}^{-}}{1+r}-\mathrm{C}=\mathcal{X}$ million $)$

Using the Eq.15, we can write:

$$
T_{C}=\frac{1+\beta}{\beta I} C-\frac{V_{g}}{I}+\frac{\mu}{I}=8.8 \text { year ) }
$$

Using the Eq.9, we can obtain: $\quad \mathrm{C}=\left(\frac{1}{2} \mathrm{k} \beta T_{c}^{2}\right)^{\frac{1}{1+\beta}}=4(\mathrm{C}$ million )

From the calculation results, we can be obtain that the construction cost of the developer in the nine-year contract period is 46 million yuan. Obviously, this result is lower than the cost the government requires, but the developer will not invest construction funds lower than the cost of the contract, because if the developer reduces the construction cost of investment in the first stage of the project, then the government will deprive the developer of the right of its continued construction of the second stage.

\section{Conclusion}

In the construction of low-rent housing projects, the negotiations of contract agreements are not only related to the profit distribution between the government and developers, but also affect the quality of the project in the construction. Determining the contract period is the key link of the negotiations of contract agreements. Therefore, based on the option game features low-rent housing projects have, the paper builds utility functions, cost-input models and decision-making models of the contract period. The influences given by construction cost, contract period and other relevant decision-making factors on the development agreement are derived, with the quantitative relationships between the contract period and its influencing factors. It indicates that by the use of growth options in the shortened contract period, developers can still ensure the quality of low-rent housing construction.

\section{References}

[1] Guoxing Zhang, Xiulin Gao, Yingluo Wang, An asymmetric duopoly investment decision-making model based on difference of option, Systems Engineering-Theory \& Practice 35(3):751-762,2015.

[2] Guangxu Wu, Xu Ren, The Game Decision Analysis of Low-rent Housing PPP Mode, Journal of Engineering Management 26(3):94-98, 2012.

[3] Wei Li \& Daijin Xi, Option Game Analysis on Symmetric Enterprise R\&D Project under Uncertain Conditions, Value Engineering (2):100-102, 2012. 
[4] Yuling Liao, Qianlin Hong, The Timing Selecting of Investment Based on Option Game, The Theory and Practice of Finance and Economics 32(172):31-34, 2011. 